\title{
Volatility spillovers and contagion between energy sector and financial assets during COVID-19 crisis period
}

\author{
Achraf Ghorbel $^{1} \mathbb{D} \cdot$ Ahmed Jeribi $^{2}$
}

Received: 2 December 2020 / Revised: 3 June 2021 / Accepted: 7 June 2021 /

Published online: 21 July 2021

(c) Eurasia Business and Economics Society 2021

\begin{abstract}
In this paper, we examine the relationship between the volatilities of the energy index, crude oil, gas prices, and financial assets (Gold, Bitcoin, and G7 stock indexes), especially during the coronavirus crisis. The study tests the presence of regime changes in the GARCH volatility dynamics of the G7 stock indexes, Bitcoin, Gold, and energy assets (energy index, oil, and gas) by using the Markov-Switching GARCH model. It estimates the dynamic correlation and volatility spillover between energy and financial assets, by using the multivariate MSGARCH models. The estimation results of the Markov-Switching-BEKK-GARCH prove the volatility spillover from energy assets to financial assets. For the high regime, the results indicate a high level of dynamic correlation between energy assets and stock indexes which proves the contagion effect of the COVID-19. On the contrary, the dynamic conditional correlation between energy assets and Gold prices decreased during the COVID-19 crisis. This paper makes an original contribution in identifying the contagion between energy and financial assets and indicates that Gold is a safe haven for all energy and financial assets during the COVID-19 crisis. However, Bitcoin cannot be considered as a safe haven during the COVID-19 pandemic when investing in energy assets (crude oil and gas).
\end{abstract}

Keywords Cryptocurrency · Gold · Energy indices · G7 stock indices · COVID-19 pandemic $\cdot$ Markov-switching GARCH

Achraf Ghorbel

ghorbelachraf@yahoo.fr

1 Faculty of Economics and Management, University of Sfax, Street of Airport, km 4.5, LP 1088, 3018 Sfax, Tunisia

2 Faculty of Economics and Management of Mahdia, University of Monastir, Monastir, Tunisia 


\section{Introduction}

The COVID-19, which began in Wuhan, China, in December 2019, has rapidly evolved from a provincial health scare to a global meltdown, throwing the world to fear. According to the European Commission for Disease Control (ECDC 2020), this pandemic has now spread to more than 200 countries around the globe causing a severe global economic recession that began affecting the world on 20 February 2020. It is significantly worsened with the exceptional increase in the number of cases and deaths caused by this pandemic, as by the end of July 2020 more than 17 million cases of COVID-19, as well as 600.000 deaths, have been detected worldwide. Opinions about the COVID-19 pandemic are currently divided. Some research organizations believe that it could trigger another global financial crisis, while others believe that the impact of the pandemic, if not quickly stopped, could be worse than the outbreak of the SARS in 2003 in China, the 2008 global financial crisis, and the Second World War combined.

The COVID-19 pandemic generated a human and health crisis. The required measures to contain the virus have resulted in an economic downturn. The International Monetary Fund's rapport indicated that, on 14 April 2020, all the G7 countries have already reached a "deep recession". The IMF has announced that global growth, which is estimated at $-3 \%$ in 2020, is "much worse" than it was during the 2009 Great Recession. According to Salisu et al. (2020) and Ghorbel and Jeribi (2021a, 2021b), the exclusion of the oil-stock nexus study from other variables during the pandemic is intentional. As the COVID-19 pandemic rages, oil prices have fallen by 30 percent, the biggest decline since the Gulf War of 1991 (Schneider \& Domonoske, 2020). Also, the collapse of oil prices caused by the 2020 Russia-Saudi Arabia oil price war opened a new battlefront for pandemic-battered economies. In the absence of a major Middle East conflict, Jefferson (2020) foresees that crude oil prices may be expected to recover by the third quarter of 2020.

The negative economic consequences of this pandemic are significant for the G7 countries. There is a disruption in global supply chains. There is also a decline in demand for imported goods and services and a decrease in international tourism and business travel. We note that the global economy has become much more integrated if we compare this situation with the SARS outbreak in 2003. China, as the root of this pandemic, now plays a far more pronounced role in the industry, commerce, tourism, and FDI. China is now a manufacturing and a top power trade giant. The economic consequences of China's negative shock would have a considerable impact on the global economy. Investors tend to look for new investment options that can deliver diversification and/or hedge benefits following periods of financial volatility experienced during the last decade. Financial markets have become more volatile and unstable due to the great uncertainty of the COVID-19 pandemic and its related economic losses (Zhang et al., 2020). At the beginning of the pandemic outbreak, Rizwan et al. (2020) and Gorbel and Jeribi (2021b) revealed a significant rise in systemic risk among the G7 countries. However, compared to the pre-COVID-19 period, China is showing some recovery. 
For decades and through various crises, the yellow metal has historically been viewed as a safe haven asset in periods of financial uncertainty (Bouri et al., 2020; Ghorbel \& Jeribi, 2021a, 2021b; Jareno et al., 2020; Selmi et al., 2018; Vardar et al., 2018). Gold values have risen significantly since the global economic and financial crises, while other commodities have sustained declines (Beckmann et al., 2015; Fakhfekh et al., 2021). During the COVID-19 pandemic, Conlon and McGee (2020), Conlon et al. (2020), Ghorbel and Jeribi (2021a), and Jeribi and Fakhfekh (2021) found that, contrary to gold, Bitcoin does not serve as a safe haven for the S\&P500. In the same line of results, Corbet et al. (2020), Ghorbel and Jeribi (2021a), and Jeribi and Fakhfekh (2021) found that both Bitcoin and Ethereum do not serve as a safe haven for international stock markets.

Studying the relation between stock markets and oil prices and vice versa began with Hamilton's (1983) work. Current pieces of Literature in this concern have expanded this research to the financial market and similar results have been identified (Arouri \& Rault, 2010; Aydogan, 2017; Ghorbel \& Jeribi, 2021b; Narayan \& Gupta, 2015; Salisu et al., 2019). The latest instability in the global economy as a result of the COVID-19 outbreak has gained a great deal of interest, including the interaction among movements in oil prices, the economy, and stock markets. Ali et al. (2020) found that, unlike gold, crude oil has the highest volatility due to the COVID-19 pandemic and the regional disputes between oil-producing nations. However, Bakas and Triantafyllou (2020) and Albulescu (2020) suggested that the uncertainty surrounding the 2020 global pandemic had a significant negative effect on the volatility of commodity markets and, in particular, on the crude oil market, with a positive but less significant impact on the yellow metal market.

After the announcement of the COVID-19 pandemic, Sharif et al. (2020) studied the connections between the shock of oil price volatility, the US financial market, geopolitical risk, and economic policy instability. They demonstrate that oil prices were influenced by the COVID-19 pandemic, which can be justified by imposed travel bans and OPEC + agreements. Salisu et al. (2020) developed a panel Vector Autoregressive (pVAR) model to evaluate the behavior of the oil-stock nexus during the COVID-19 pandemic. Their findings show a unidirectional causality from oil price returns to stock returns in the pre-COVID-19 period, while during the 2020 global pandemic, a bi-directional causality between crude oil price and stock returns is reported. Chang et al. (2020) examined the risk spillover effects of the energy sectors in the USA, Europe, and Asia stock markets during three types of global crises. Their results indicated that for low extreme oil returns during the coronavirus crises, investors are more likely to display herding in the stock market. In addition, during the 2020 global pandemic, investors panic so they may unwisely sell their financial assets. In the same line of research, Mazur et al. (2020) found that natural gas, healthcare, software, and food stocks earn high positive returns, whereas, petroleum, entertainment, real estate, and hospitality sectors stocks fall dramatically during the COVID-19 pandemic. Adekoya and Oliyide (2021) and Gorbel and Jeribi (2021b) show that the latter cited pandemic is responsible for risk transmission across commodity and financial markets. Contrary to gold, Ghorbel and Jeribi (2021b) found that Bitcoin cannot be considered as a safe haven during the global pandemic when investing in crude oil. 
Based on the above-mentioned studies, this paper extends the related literature and makes an original contribution in identifying the contagion between energy, traditional, and digital financial assets and indicates that Gold is a safe haven when investing in energy assets during the COVID-19 crisis. Bitcoin is considered a safe haven only when investing in the energy index. In this study, firstly, we apply the combined Markov Switching model and GARCH model on the G7 stock indices and the energy index (NYSE energy index), oil (WTI), gas (Henry Hub Natural Gas Spot Price), Bitcoin, and Gold prices. The choice of these countries is explained by the fact that they hold more than $2 / 3$ of the world's net wealth. In addition, they are the most affected by the COVID-19 (Amar et al., 2021). Secondly, we estimate the MSBEKK-GARCH model. Third, by using the MSDCC-GARCH model, we analyze the dynamic correlations between the studied assets to investigate the contagion effects of the COVID-19 pandemic.

The layout of this paper is as follows. Our econometric methodology is discussed in Sect. 2. Section 3 is devoted to highlighting the relevant data and empirical findings. Finally, Sect. 4 concludes.

\section{Empirical methodology}

First, referring to Ardia et al. (2018) and Sayed and Auret (2020), we estimate the Markov-Switching GARCH model for all series. Let $y_{t}$ be the daily series log-returns at time $t$. Following Ardia et al. (2018), we identify the MSGARCH model as:

$$
y_{t} /\left(s_{t}=k, I_{t-1}\right) \sim D\left(0, h_{k, t}, \xi_{k}\right)
$$

where $D\left(0, h_{k, t}, \xi_{k}\right)$ is a continuous distribution with a zero mean, a time-varying conditional variance $h_{k, t}$, in regime $k$, and a vector $\xi_{k}$ of additional shape parameters. The state variable $s_{t}$ evolves according to a first-order homogeneous Markov chain with a finite number of states k. $I_{t-1}$ Denotes the information set available up to $t-1$. For low and high volume regimes $\left(s_{t}=1\right.$ and $\left.s_{t}=2\right)$, we estimate the MSGARCH(1,1) model of Bollerslev (1986) for energy and financial assets:

$$
h_{k, t}=\omega_{k}+\alpha_{k} y_{t-1}^{2}+\beta_{k} h_{k, t-1}
$$

Second, we extend the standard multivariate BEKK-GARCH model of Engle and Kroner (1995) to allow for the presence of regime shifts. We used the bivariate BEKK-MSGARCH for studying the transmission mechanism of shocks (volatility) originating from energy assets (energy index, oil, and gas) to financial assets (G7 stock indices, gold, and cryptocurrency).

According to Haas et al. (2009), we derive the multivariate BEKK-MSGARCH process:

$$
\boldsymbol{r}_{t}=\emptyset+\boldsymbol{e}_{t}
$$




$$
\boldsymbol{e}_{t, s t}=\boldsymbol{H}_{\Delta_{t}}^{1 / 2} \boldsymbol{E}_{t} E_{t} / \Omega_{t-1} \rightarrow N\left(0_{M \times 1}, I_{M}\right)
$$

Both the return $r$ and the variance $H$ are made regime-dependent. Let $r_{t}$ be the return matrix at time $t$, modeled as a constant plus a disturbance term. $\Phi$ constitutes the constant vector, $I_{M}$ denotes the identity matrix of dimension $M$. The transition between the successive states is governed by a first-order Markov process $\left\{\Delta_{t}\right\}$ with finite state space $S=\{1,2, \ldots, k\}$ and a primitive (i.e., irreducible and aperiodic) fixed $k \times k$ transition probability matrix $P$.

Where the transition probabilities are given by $p_{i j}=p \quad\left(\Delta_{t}=j / \Delta_{t-1}=i\right)$, $i, j=1, \ldots, k$. The regime-dependent covariance matrix $H$ is assumed to follow a Multivariate Markov Switching GARCH (p,q,k) introduced by Bollerslev (1986);

$$
h_{i t}=\omega_{i}+\sum_{i=1}^{q} \alpha_{i j} \varepsilon_{t-i}^{2}+\sum_{j=1}^{p} \beta_{i j} h_{j, t-j}, \quad j=1, \ldots, k
$$

where $\alpha_{i}=\left[\alpha_{i 1}, \ldots, \alpha_{i k}\right], i=1, \ldots, q$ and $\beta_{i}=\left[\beta_{i 1}, \ldots, \beta_{i k}\right], i=1, \ldots, p$ are parameter matrices of appropriate dimension. The number of the independent element of the regime-dependent conditional covariance matrices $H_{j t}$ is $N=M /(M+1) / 2$.

To make the application trustworthy, parameter constraints are required. Such a parameterization is provided by the Baba et al. (1990) (BEKK) which specifies the conditional volatility as:

$$
H_{j t}=\omega_{0 j}^{*} \omega_{0 j}^{*^{\prime}}+\sum_{l=1}^{L} \sum_{i=1}^{q} \alpha_{i j, l}^{*} e_{t-i} e_{t-i}^{\prime} \alpha_{i j, l}^{*^{\prime}}+\sum_{l=1}^{L} \sum_{i=1}^{q} \beta_{i j, l}^{*} H_{t-i} \beta_{i j, l}^{*^{\prime}}, j=\{1, \ldots, k\}
$$

Where $\omega_{0 j}^{*}$ are $k \times k$ lower triangular matrices of state-dependent coefficients, $L$ is the lag operator. $\omega_{0 j}^{*}, \alpha_{i j}^{*}$ and $\beta_{i j}^{*}$ are state-dependent matrices. In variance decomposition, first, we estimate $\alpha_{i j}^{*}=\alpha_{\text {energy,asset } ; S_{t}=i}^{*}$ and $\beta_{i j}^{*}=\beta_{\text {energy,asset } ; S_{t}=i}^{*}$ from energy index (NY energy index) to financial assets $(i=$ energy index and $j=$ asset $)$ for high volume regime $\left(S_{t}=1\right)$ and low volume regime $\left(S_{t}=2\right)$. Second, we estimate $\alpha_{i j}^{*}=\alpha_{\text {oil,asset } ; S_{t}=i}$ and $\beta_{i j}^{*}=\beta_{\text {oil,asset } S_{t}=i}^{*}$ from Oil (SSE) to financial assets ( $i=$ oil and $j=$ asset) for high volume regime $\left(S_{t}=1\right)$ and low volume regime $\left(S_{t}=2\right)$. Finally, we estimate $\alpha_{i j}^{*}=\alpha_{\text {gas }, a s s e t ; S_{t}=i}^{*}$ and $\beta_{i j}^{*}=\beta_{\text {gas,asset } ; S_{t}=i}^{*}$ from the gas spot to financial assets $(i=$ gas and $j=$ asset $)$ for high volume regime $\left(S_{t}=1\right)$ and low volume regime $\left(S_{t}=2\right)$.

Third, referring to Billio and Caporin (2005), we consider the MSDCC-GARCH model in the following equation:

$$
Q_{t}=\left[1-\alpha\left(s_{t}\right)-\beta\left(s_{t}\right)\right] \bar{Q}\left(s_{t}\right)+\alpha\left(s_{t}\right) \eta_{t-1} \eta_{t-1}+\beta\left(s_{t}\right) Q_{t-1}
$$




$$
\bar{Q}\left(s_{t}\right)=\frac{1}{T} \sum_{i=1}^{T} \eta_{t-1} \eta_{t-1}
$$

The Markov chain is governed by the following transition matrix: $P=\left\{p_{j i} i, j=1, \ldots S\right\}$. Where $S$ is the number of regimes, $S=1$ for the low regime volatilities and $S=2$ for the high regime volatilities. ${ }^{1}$ For a high volume regime $(S=2)$, we estimate the dynamic conditional correlation between energy assets (energy index, oil, and gas) and financial assets.

\section{Data and results}

\subsection{Data and descriptive statistics}

Adjusted closing-price data are relevant to the G7 stock indices (S\&P500; FTSE; Nikkei; CAC40; Dax30; S\&P/TSX and FTSEMIB), energy index (NYSE energy index), oil (WTI), and gas (Henry Hub Natural Gas Spot Price). Also, we add the Bitcoin and gold price, regarding the period ranging from January 1, 2016, to July 23, 2020, on a daily frequency basis. ${ }^{2}$ We used Oxmetrics software. ${ }^{3}$ Daily returns are defined by $y_{t}=\ln \left(p_{t} / p_{t-1}\right)$, with $p_{t}$ standing for the series respective closing price on day $t$.

Table 1 presents the statistics summary of the energy index, oil, gas, stock indices, Bitcoin, and gold returns. All assets recorded mean positive returns during this period, except the energy index, gas, and Italian stock index (FTSEMIB). Whereas Gold presents the lowest risk, and Bitcoin presents the highest risk. All asset returns have kurtosis values higher than three and the distribution of returns is negatively and positively skewed for all-time assets, which indicates that all return markets are far from the normal distribution. Therefore, the assumption of Gaussian returns is rejected by the Jarque-Bera test for all assets. The empirical statistics of the Engle (1982) test for conditional heteroscedasticity are significant for all cases suggesting the presence of $\mathrm{ARCH}$ effects in returns which justifies our choice of GARCH models.

\subsection{Empirical results}

Figure 1 illustrates the volatilities of the high $(S=2)$ and low $(S=1)$ regimes for each asset extracted by the MSGARCH(1,1) model of Eq. 2. Figure 1 plots the time-varying smoothed probabilities for the low- and high-volatility regimes. The stock market, as well as Bitcoin and Gold, are assessed in regime $i$ if the associated smoothed probability $\mathrm{P}(\mathrm{St}=\mathrm{i})$ is higher than 0.5 . Concerning the plots, we note that

\footnotetext{
1 For more details see Billio and Caporin (2005).

2 The database was collected from the Coin Market Cap, Datastream and ABC bourse.

3 Source: https://www.timberlake.co.uk/software/oxmetrics.html.
} 


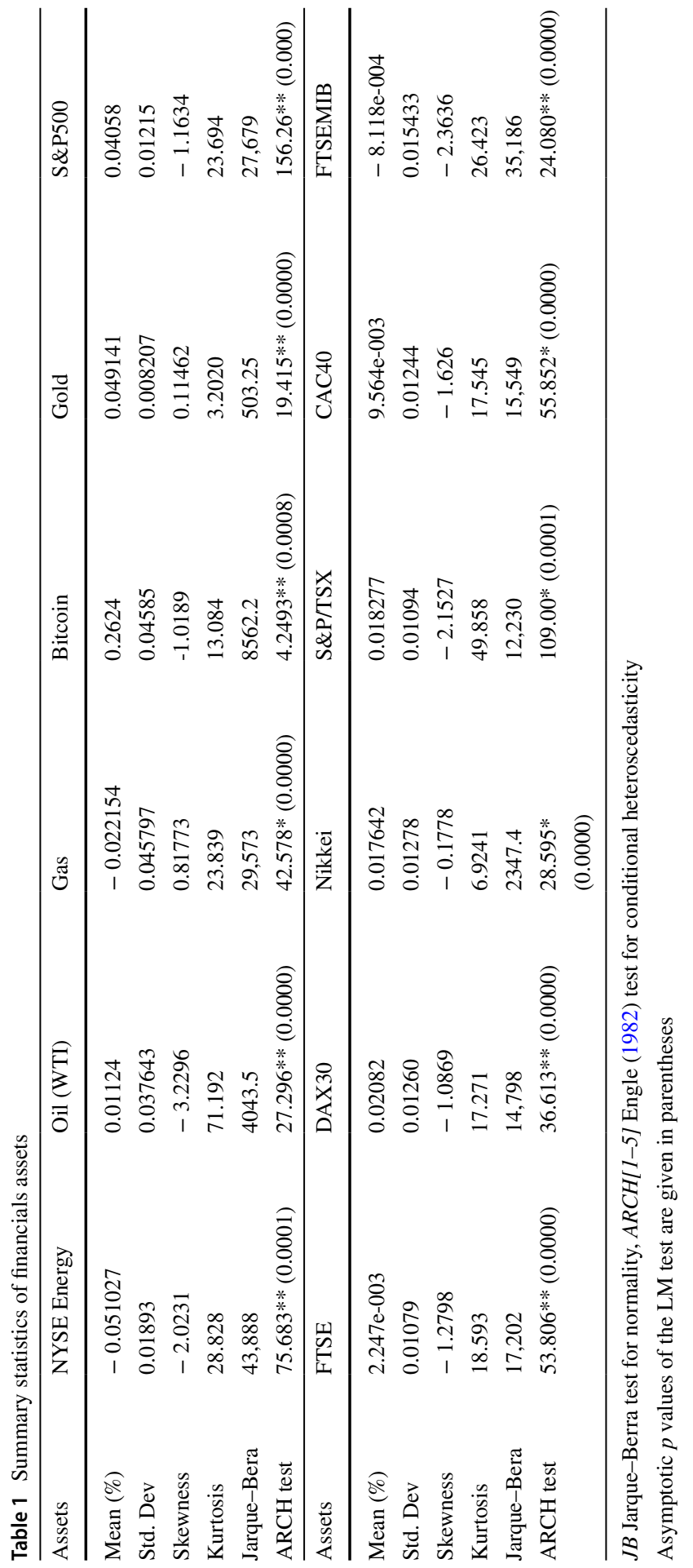



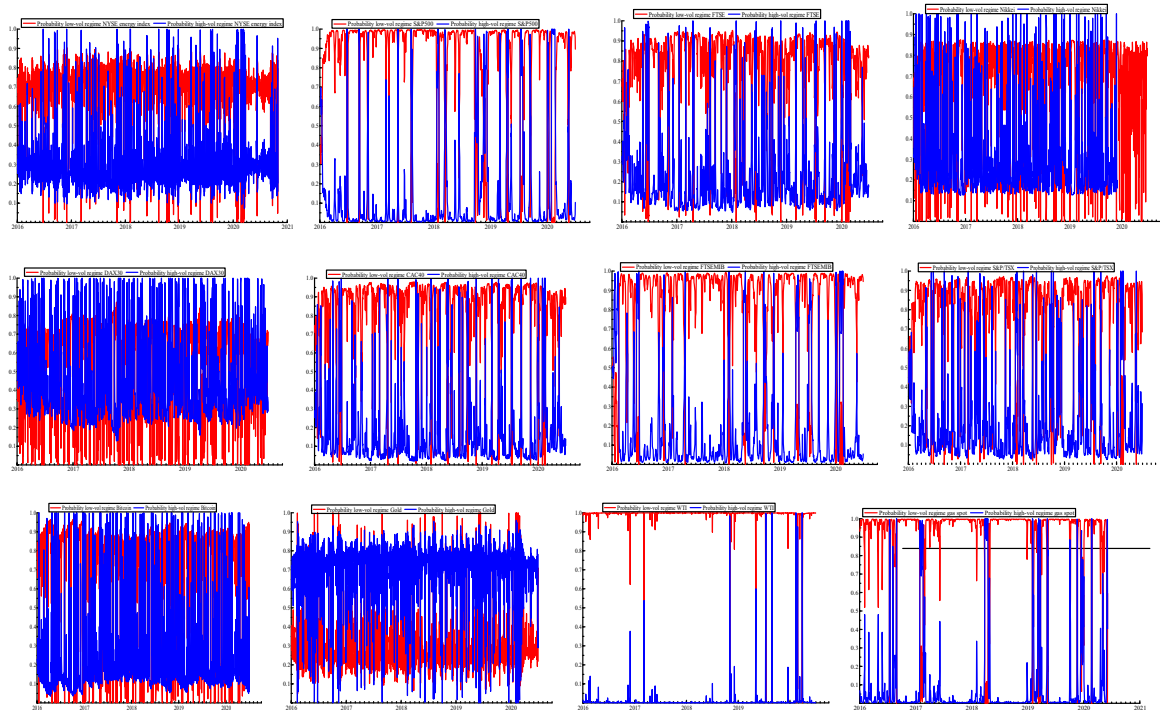

Fig. 1 Volatilities of low and high regimes for bitcoin, gold and stock indices

there are similar regime shift patterns in English, Japanese, Italian, and French stock markets before the 2020 global pandemic. More specifically, all these markets experienced a low volatility regime. However, German and Canadian stock markets registered a high volatility regime. The low- and high-volatility regimes switch among them for the US stock market as well as the energy index, Gas, oil, Gold, and Bitcoin until the end of 2019. During the COVID-19 outbreak, all assets experienced a high volatility regime except for Gold, which can be considered a safe-haven asset for investors during a crisis.

Table 2 presents the estimation results of the Markov Switching-BEKK$\operatorname{GARCH}(1,1,2)$ model, from the energy index to financial assets. The estimation results of the MSGARCH-BEKK $(1,1,2)$ model support the presence of significant volatility spillover from the energy index to the stock indexes, in two regimes (high and low volatility). In other words, the current conditional volatility of each stock index depends not only on its past volatility but also on the past volatility of the energy index. On the contrary, the estimation results of the Markov Switching -BEKK-GARCH $(1,1,2)$ model, from the energy index to Bitcoin show that the GARCH parameters for the two regimes are not significant. So, the current conditional volatility of Bitcoin depends only on its past volatility. In Table 2, the results of estimating $\mathrm{ARCH}\left(\alpha_{\text {energy,Bitcoin, } s_{t}=1}\right.$ and $\left.\alpha_{\text {enegy,Bitcoin }, s_{t}=2}\right)$ parameters show evidence of shock transmission effect from energy index to cryptocurrency (Bitcoin). It should be noticed, though, that for the pair energy index-cryptocurrency, $\left(\alpha_{\text {energy,Bitcoin, } s_{t}}\right)$ is significantly positive, in the two regimes. Consequently, the past news about shocks in the energy index positively affects the current conditional volatility of cryptocurrency. 


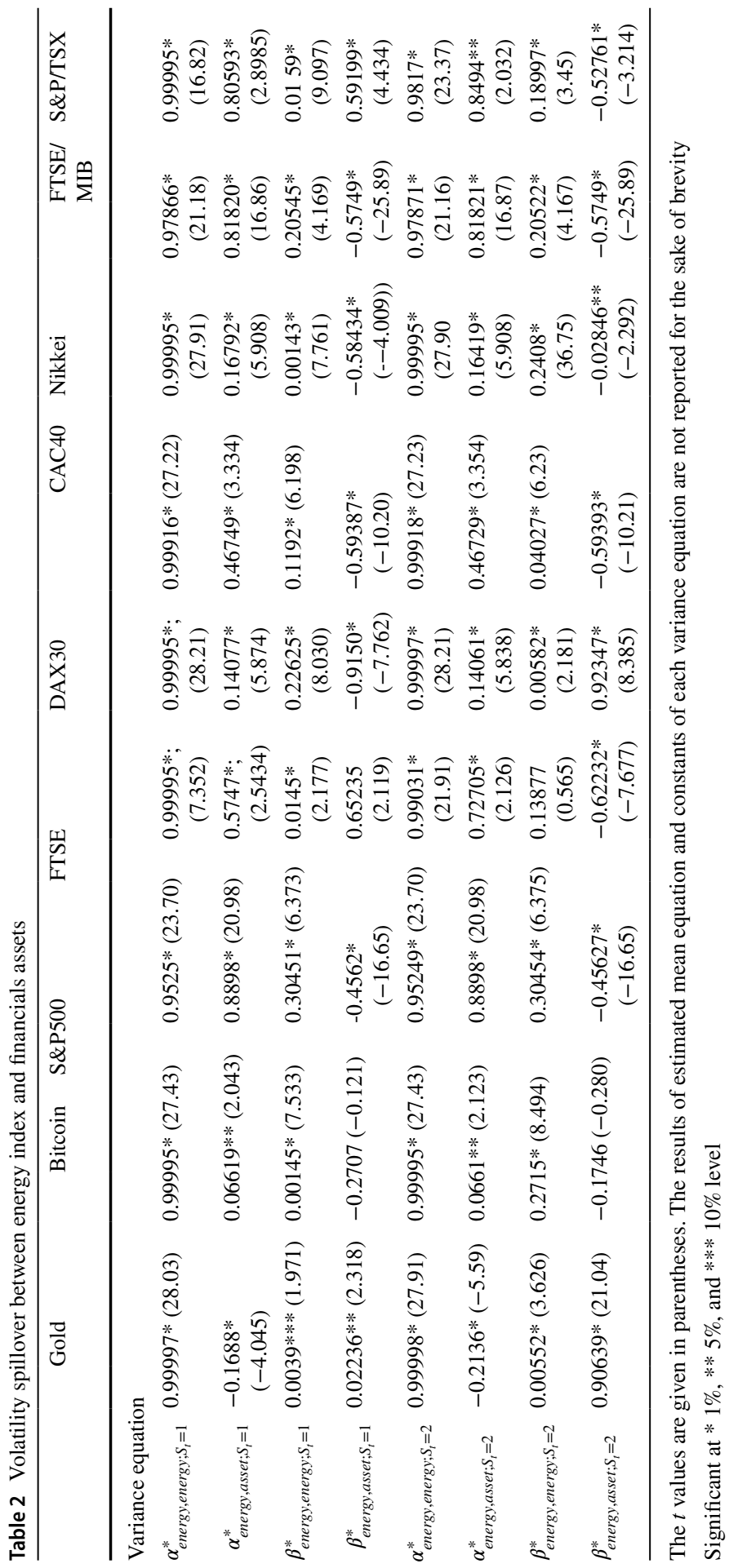


In Table 2, the results of estimating $\mathrm{ARCH}\left(\alpha_{\text {energy,Gold, } s_{t}=1}\right.$ and $\left.\alpha_{\text {energy, Gold }, s_{t}=2}\right)$ parameters show evidence of shock transmission effect from the energy index to Gold returns. It should be noticed, though, that for the pair energy index-Gold, $\left(\alpha_{\text {energy,Gold }, s_{t}=1} ; t=1\right.$ and $\left.t=2\right)$ is significantly negative in the two regimes. Consequently, the past news about shocks in the energy index negatively affects the current conditional volatility of Gold. The estimation of GARCH $\left(\beta_{\text {energy, Gold, } s_{t=1}}\right.$ and $\beta_{\text {energy,Gold, } s_{t=2}}$ ) parameters is significantly positive between energy and Gold. Consequently, the current conditional volatility of Gold depends not only on its past volatility but also on the past volatility of the energy index.

Table 3 presents the estimation results of the Markov Switching-BEKK-GARCH $(1,1,2)$ model from oil to financial assets. The empirical results from the Markov Switching GARCH-BEKK $(1,1,2)$ model support the shock transmission volatilities from oil to G7 stock indexes in a regime of lower and higher volatilities. In essence, unanticipated events in the oil returns can stimulate higher volatility in the stock indexes. The estimation of the GARCH parameters supports the presence of significant volatility spillover from the Oil to the stock indexes, in two regimes (high and low volatility). In other words, the current conditional volatility of the stock index depends not only on its past volatility but also on the past Oil volatility.

In Table 3 , the results of estimating $\mathrm{ARCH}\left(\alpha_{\text {oil,Bitcoin, } s_{t}} ; t=1\right.$ and $\left.t=2\right)$ parameters show evidence of shock transmission effect between Oil and cryptocurrency (Bitcoin). It should be noticed, though, that for the pair Oil-cryptocurrency, $\left(\alpha_{\text {oil,Bitcoin,s } s_{t}}\right.$; $t=1$ and $t=2$ ) is significantly positive in the two regimes. Consequently, the past news about shocks in Oil positively affects the current conditional volatility of cryptocurrency. The estimation of GARCH $\left(\beta_{\text {oil,Bitcoin, } s_{t}} ; t=1\right.$ and $\left.t=2\right)$ parameters is significantly positive between Oil and cryptocurrency. Consequently, the current conditional volatility of cryptocurrency depends not only on its past volatility but also on the past volatility of the Oil.

In the two regimes (lower and higher volatilities), the ARCH coefficients $\left(\alpha_{\text {oil,Gold, } s_{t}} ; t=1\right.$ and $\left.t=2\right)$ document a negative effect of shock transmission volatilities from Oil to Gold. In essence, unanticipated events in the Oil price can stimulate higher volatility in the Gold returns.

By focusing on the GARCH parameter, we found that there is strong evidence of a significant negative transmission of volatility $\left(\beta_{\text {oil Gold, } s_{t}} ; t=1\right.$ and $\left.t=2\right)$ from Oil to Gold returns in the two regimes. Consequently, the current conditional volatility of Gold depends not only on its past volatility but also on the past volatility of Oil.

Table 4 presents the estimation results of the Markov Switching-BEKK-GARCH $(1,1,2)$ model from Gas price to financial assets. The estimation results of the MSGARCH-BEKK $(1,1,2)$ model support the presence of significant volatility spillover from the Gas to the stock indexes in the two regimes (high and low volatility). In other words, the current conditional volatility of the stock index depends not only on its past volatility but also on the past volatility of the Gas price. Also, the results of estimating $\mathrm{ARCH}\left(\alpha_{\text {gas,asset, },_{t}} ; t=1\right.$ and $\left.t=2\right)$ parameters show evidence of shock transmission effect between gas and the stock indexes. It should be noticed, though, that for the pair Gas-stock index, $\left(\alpha_{\text {gas,asset, }, s_{t}} ; t=1\right.$ and $\left.t=2\right)$ is significantly positive 


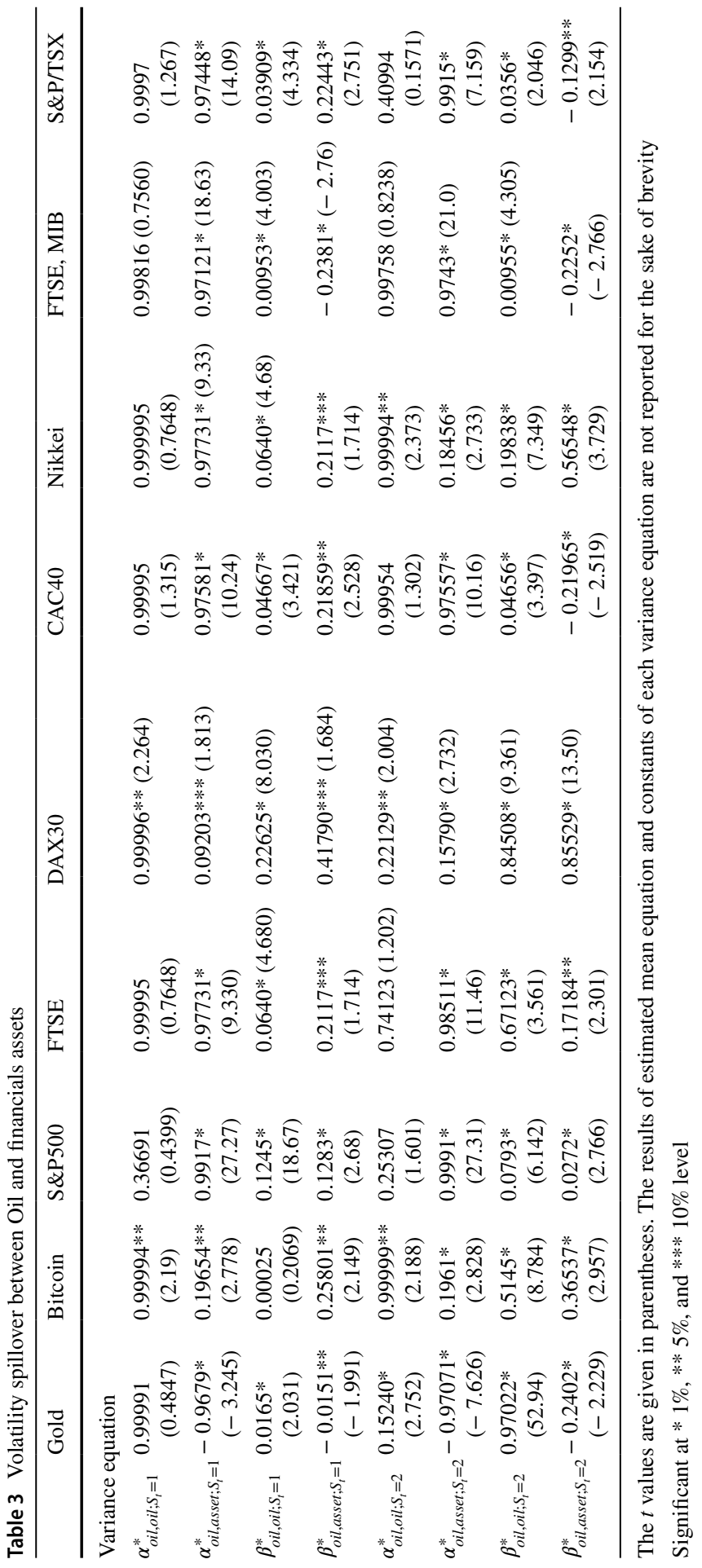




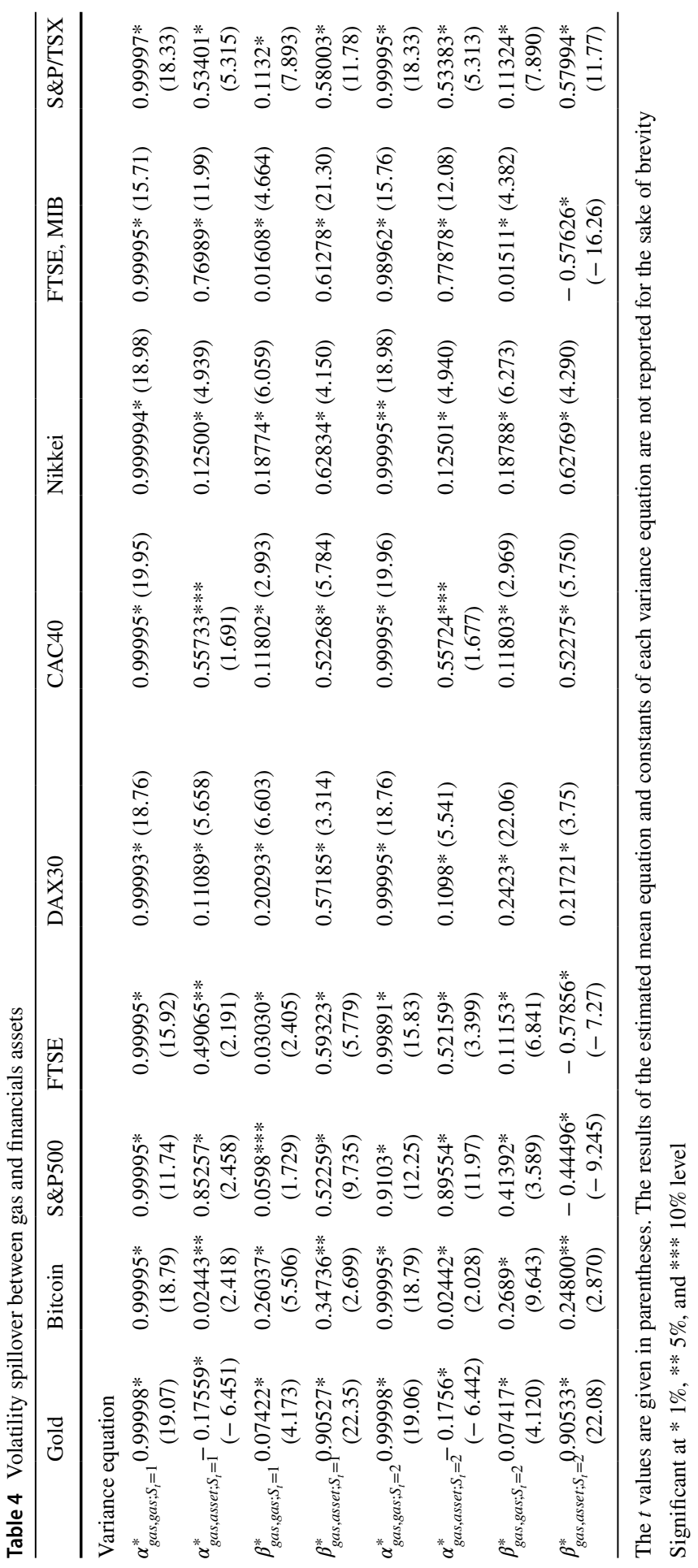



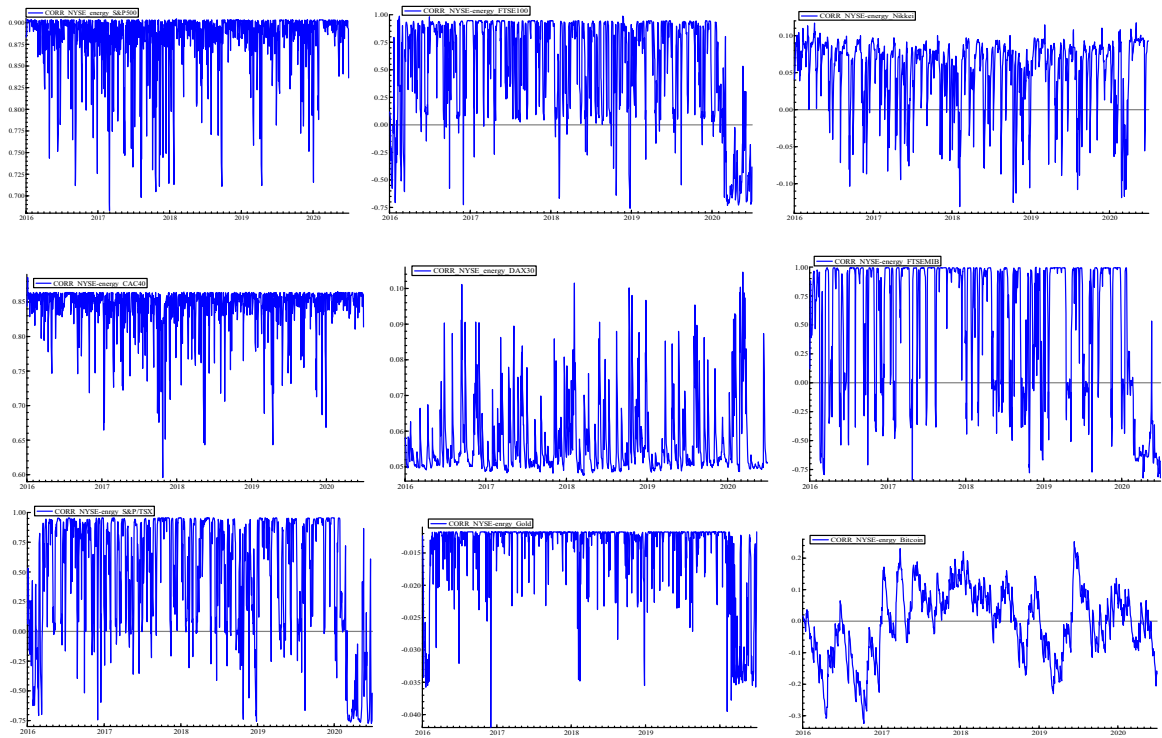

Fig. 2 Dynamic correlation between NYSE energy index and financial assets for high volatility regime

in the two regimes. Consequently, the past news about shocks in Gas prices positively affects the current conditional volatility of the stock index.

In Table 4, the estimation results of the Markov Switching-BEKK-GARCH $(1,1,2)$ model, from Gas price to Bitcoin show that the GARCH parameters for the two regimes are significant. The results of estimating $\mathrm{ARCH}\left(\alpha_{\text {gas,Bitcoin, } s_{t}=1}\right.$ and $\alpha_{\text {gas }, \text { Bitcoin }, s_{t}=2}$ ) parameters show evidence of shock transmission effect from Gas price to cryptocurrency (Bitcoin). It should be noticed, though, that for the pair Gascryptocurrency, $\left(\alpha_{\text {gas,Bitcoin, } s_{t}}\right)$ is significantly positive in the two regimes. Consequently, the past news about shocks in Gas prices positively affects the current conditional volatility of cryptocurrency. The estimation of GARCH ( $\beta_{\text {gas,Bitcoin, } s_{t=1}}$ and $\beta_{\text {gas,Bitcoin, } s_{t=2}}$ ) parameters is significantly positive between Gas and cryptocurrency. Consequently, the current conditional volatility of cryptocurrency depends not only on its past volatility but also on the past volatility of the Gas prices.

In Table 4 , the results of estimating ARCH $\left(\alpha_{\text {gas }, \text { Gold }, s_{t}=1}\right.$ and $\left.\alpha_{\text {gas, Gold }, s_{t}=2}\right)$ parameters show evidence of shock transmission effect from Gas to Gold returns. It should be noticed, though, that for the pair Gas-Gold, $\left(\alpha_{\text {gas,Gold, } s_{t}} ; t=1\right.$ and $\left.t=2\right)$ is significantly negative in the two regimes. Consequently, the past news about shocks in Gas prices negatively affects the current conditional volatility of Gold. The estimation of GARCH ( $\beta_{\text {gas }, \text { Gold } s_{t=1}}$ and $\beta_{\text {gas }, \text { Gold }, s_{t=2}}$ ) parameters is significantly positive between Gas and Gold. Consequently, the current conditional volatility of Gold depends not only on its past volatility but also on the past volatility of the Gas prices.

Figures 2, 3, and 4 present the dynamic correlation between the G7 stock market indices and the NYSE energy index, WTI, and Natural Gas Spot, respectively, for 

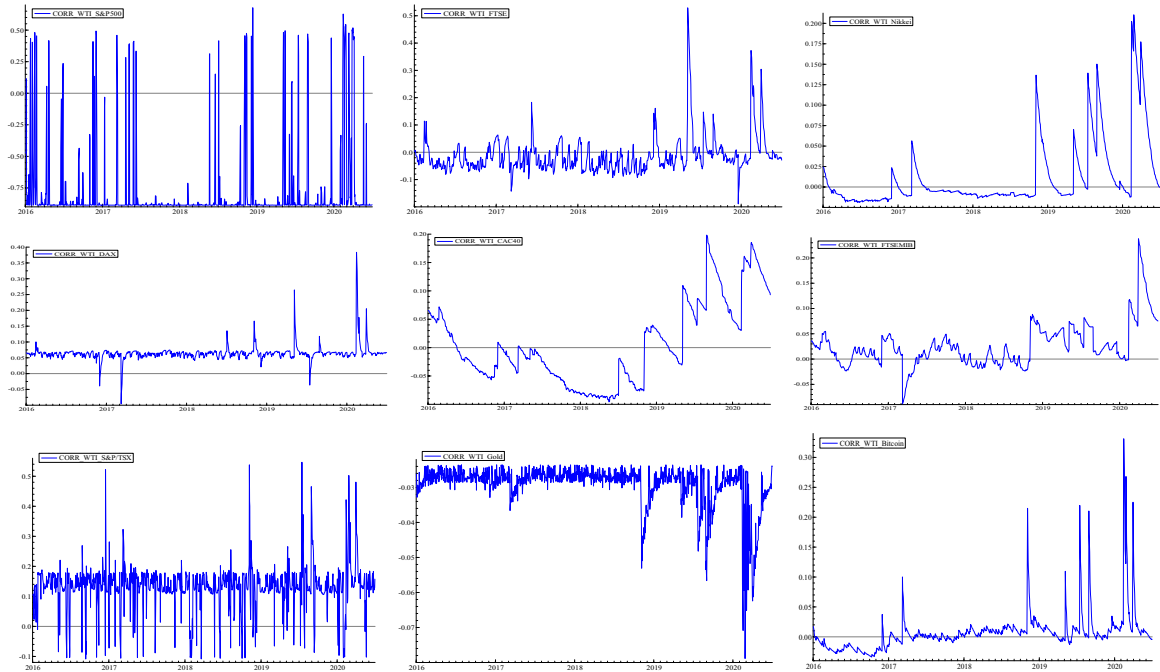

Fig. 3 Dynamic correlation between Oil and financial assets for high volatility regime
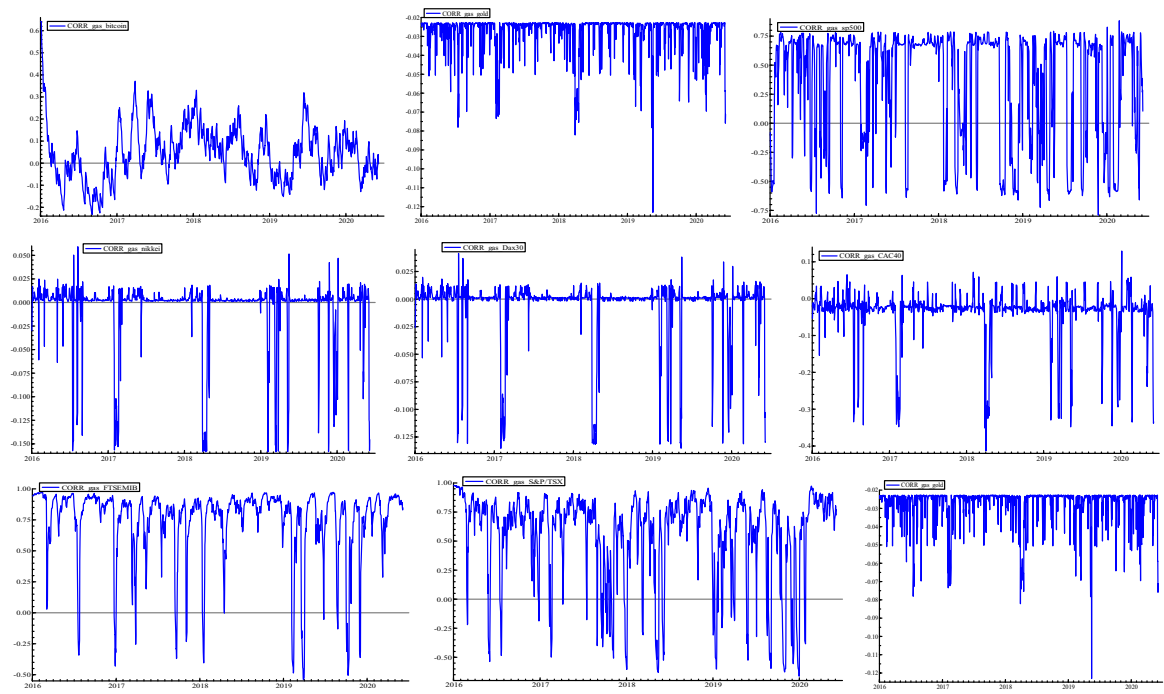

Fig. 4 Dynamic correlation between Gas and financial assets for high volatility regime

the high regime. Figure 2 shows high and positive dynamic relationships between the NYSE energy index and the S\&P500 as well as CAC 40. However, we observe a low and positive correlation between DAX30 and the NYSE energy index. The correlation became negative for the British, Canadian, and Italian stock market indices during the 2020 global pandemic. This can be explained by the fact that investors' and policy uncertainties have significantly raised. In addition, the global financial 
cycle is immensely altered. The dynamic relationship between the NYSE energy index and the yellow metal is always negative. As for Bitcoin, the dynamic correlation with the NYSE energy index switch between negative and positive values and reaches its lowest level during the COVID-19 pandemic. Gold and Bitcoin can be considered as safe havens during the global pandemic when investing in the NYSE energy stocks. This result is consistent with that of Gaspareniene et al. (2018) and Robiyanto et al. (2019). However, it is inconsistent with that of Conlon and McGee (2020) and Corbet et al. (2020). Figures 3 and 4 show that, the dynamic relationships between Oil and Gas prices on the one hand, and G7 stock market prices, on the other hand, switch between low and high levels with different levels for each stock market. It proves the volatility spillover from energy assets to financial assets. Contrary to the Japanese stock market, the US and Canadian stock markets are the most correlated with the WTI. In addition, the US, Italian, and Canadian stock markets are the most correlated with Gas prices. These results are consistent with Chang et al. (2020) and Adekoya and Oliyide (2021). Few important findings are evidenced in Table 5. In fact, our findings indicate also that the correlations for the couples WTI-Gold, WTI-Bitcoin, and Gas-Gold as well as Gas-Bitcoin are symmetric. During the COVID-19 pandemic, the correction between crude oil and Gas on the one hand, and the yellow metal, on the other hand, reached its lowest level. However, the correction between crude oil as well as Gas and Bitcoin reached its highest level. Contrary to Gold, Bitcoin cannot be considered as a safe haven during the COVID19 pandemic for investors that purchase crude oil and Gas as well as energy producers. This result confirms that of Conlon and McGee (2020) and Corbet et al. (2020).

\section{Conclusion}

This paper performs a general Markov-Switching GARCH model for modeling structural breaks for the energy sector index, Oil, Gas, cryptocurrency, G7 stock indices, and Gold. We show that the energy assets, Bitcoin, gold, and stock indices exhibit regime changes in their volatilities dynamics. The estimation results of the MSGARCH-BEKK $(1,1,2)$ model support the presence of significant volatility spillover from the energy index to the stock indexes in two regimes, especially in high volatility. In fact, the estimation results of the Markov Switching-BEKKGARCH $(1,1,2)$ model, show that the past news about shocks in the energy index positively affects the current conditional volatility of stock indices and cryptocurrency, however, it negatively affects the current conditional volatility of Gold. In other words, the current conditional volatility of each stock index and Gold depends not only on its past volatility but also on the past volatility of the energy index.

The estimation results of the MSBEKK-GARCH prove a significant effect of choc from Oil to financial assets (G7 stock indexes, Gold, and Bitcoin), on the one hand, and from Gas to financial assets, on the other hand. In other words, the stock indices and Gold depend not only on their past volatility but also on past volatilities of Oil and Gas. When focusing on the time-varying correlation between the G7 stock market indices and the energy index, WTI and Natural Gas Spot, respectively, we found high and positive dynamic relationships between the energy index and the 


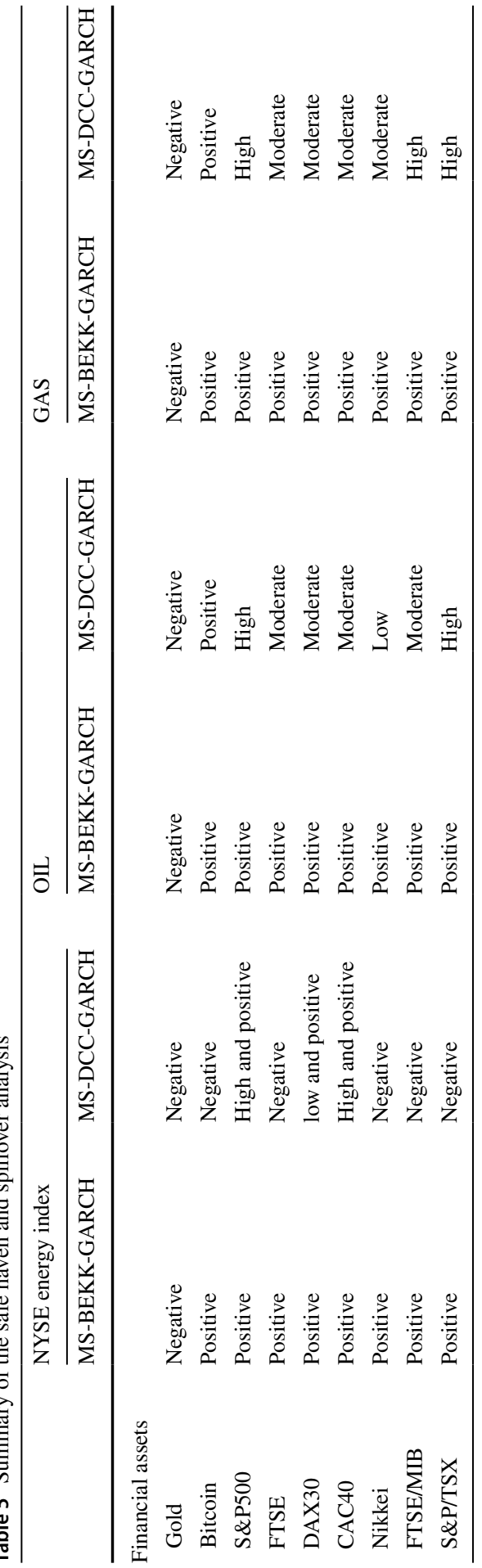


S\&P 500 as well as CAC 40. The correlation between the energy index and other G7 indices switches between low and high levels. In addition, we argue that Gold and Bitcoin can be considered as safe-haven assets during the global pandemic when investing in the stock indices. We show also that the dynamic relationships between Oil and G7 stock markets, on the one hand, and Gas price and G7 stock markets, on the other hand, switch between low and high levels with different levels for each stock index. Contrary to Gold, Bitcoin cannot be considered as a safe haven during the COVID-19 pandemic when investing in energy assets (crude oil and Gas).

The empirical results have implications for both institutional and retail investors, risk management, as well as for economic and financial policies, highlighting the prevalence of tail behavior and persistent asymmetric nature of risk spillovers. Thus, we draw two main managerial implications. First, the G7 financial market regulators should have a solution to immediately support the market when fear is overwhelming. In this case, market crash risk can be managed in extreme cases. Second, both investors and regulators should implement hedging or safe haven strategies that have been largely ignored by many analysts and policymakers especially during the SARS crisis, not least by those who have been involved with energy issues. From an investing point of view, Oil prices can affect stock prices through their effect on potential corporate cash flows and indirectly through the interest rate used to discount future cash flows. However, macroeconomic variables adjust based on the oil-stock relationship aids policy-making by helping to understand the economy's sensitivity to both internal (due-to-stock) and external (due-to-oil) shocks. Thus, the behavior of the Oil and stock markets, especially during the pandemic, is therefore essential to policy-making and to achieving better macroeconomic outcomes.

\section{Declarations}

Conflict of interest The author declares that he has no conflict of interest.

\section{References}

Adekoya, O., \& Oliyide, J. (2021). How COVID-19 drives connectedness among commodity and financial markets: Evidence from TVP-VAR and causality-in-quantiles techniques. Resources Policy, 70, 101898.

Albulescu, C. (2020). Coronavirus and oil price crash: a note. arXiv: 2003.06184

Ali, M., Alam, N., \& Rizvi, S. A. R. (2020). Coronavirus (COVID-19) - an epidemic or pandemic for financial markets. Journal of Behavioral and Experimental Finance, 27, 100341.

Amar, A. B., Belaid, F., Youssef, A. B., Chiao, B., \& Guesmi, K. (2021). The unprecedented reaction of equity and commodity markets to COVID-19. Finance Research Letters, 38, 101853.

Ardia, D., Keven, B., Kris, B., \& Leopoldo, C. (2018). Forecasting risk with Markov-Switchinggarch models: a large-scale performance study. International Journal of Forecasting, 34, 733-747.

Arouri, M. E. H., \& Rault, C. (2010). Causal relationships between oil and stock prices: Some new evidence from gulf oil-exporting countries. Economie Internationale, 2, 41-56.

Aydogan, B. (2017). Sentiment dynamics and volatility of international stock markets. Eurasian Business Review, 7, 407-419.

Baba, Y., Engle, R.F., Kraft, D., \& Kroner, K.F. (1990). Multivariate simultaneous generalized ARCH. Manuscript, Department of Economics, University of California, San Diego 
Bakas, D., \& Triantafyllou, A. (2020). Commodity price volatility and the economic uncertainty of pandemics. Economics Letters, 90, 109283.

Beckmann, J., Berger, T., \& Czdaj, R. (2015). Does gold act as a hedge or a safe haven for stocks? A smooth transition approach. Economic Modelling, 48, 16-24.

Billio, M., \& Caporin, M. (2005). Multivariate Markov switching dynamic conditional correlation GARCH representations for contagion analysis. Statistical Methods and Applications, 14, 145-161.

Bollerslev, T. (1986). Generalized autoregressive conditional heteroskedasticity. Journal of Econometrics, 31, 307-327.

Bouri, E., Shahzad, J., Roubaud, D., Kristoufek, L., \& Lucey, B. (2020). Bitcoin, gold, and commodities as safe havens for stocks: New insight through wavelet analysis. The Quarterly Review of Economics and Finance. https://doi.org/10.1016/j.qref.2020.03.004

Chang, C., McAleer, M., \& Wang, Y. (2020). Herding behaviour in energy stock markets during the global financial crisis, SARS, and ongoing COVID-19. Renewable and Sustainable Energy Reviews, $134,110349$.

Conlon, T., \& McGee, R. (2020). Safe haven or risky hazard? Bitcoin during the COVID-19 bear market. Finance Research Letters, 35, 101607.

Conlon, T., Corbet, S., \& McGee, R. (2020). Are cryptocurrencies a safe haven for equity markets? An international perspective from the COVID-19 pandemic. Research in International Business and Finance, 54, 101248.

Corbet, S., Larkin, C., \& Lucey, B. (2020). The contagion effects of the COVID-19 pandemic: Evidence from gold and cryptocurrencies. Finance Research Letters, 35, 101554.

Engle, R. F. (1982). Autoregressive conditional heteroscedasticity with estimates of the variance of United Kingdom inflation. Econometrica, 50(4), 987.

Engle, R., \& Kroner, K. (1995). Multivariate simultaneous GARCH. Econometric Theory, 11, $122-150$.

Fakhfekh, M., Jeribi, A., Ghorbel, A., \& Hachicha, N. (2021). Hedging stock market prices with WTI, Gold, VIX and cryptocurrencies: A comparison between DCC, ADCC and GO-GARCH models. International Journal of Emerging Markets. https://doi.org/10.1108/IJOEM-03-2020-0264

Gaspareniene, L., Remeikiene, R., Sadeckas, A., \& Ginevicius, R. (2018). Gold Investment Incentives: An empirical identification of the main gold price determinants and prognostication of gold price future trends. Economics and Sociology, 11(3), 248-264.

Ghorbel, A., \& Jeribi, A. (2021a). Investigating the relationship between volatilities of cryptocurrencies and other financial assets. Decisions in Economics and Finance. https://doi.org/10.1007/ s10203-020-00312-9

Ghorbel, A., \& Jeribi, A. (2021b). Contagion of COVID-19 pandemic between oil and financial assets: The evidence of multivariate Markov switching GARCH models. Journal of Investment Compliance. https://doi.org/10.1108/joic-01-2021-0001

Haas, M., Mittnik, S., \& Paolella, M. S. (2009). Asymmetric multivariate normal mixture GARCH. Computational Statistics \& Data Analysis, 53(6), 2129-2154.

Hamilton, J. D. (1983). Oil price and the macroeconomy since World War II. Journal of Political Economy, 91, 228-248.

Jareno, F., Gonzalez, M., Tolentino, M., \& Sierra, K. (2020). Bitcoin and gold price returns: A quantile regression and NARDL analysis. Resources Policy, 67, 101666.

Jefferson, M. (2020). A crude future? COVID-19s challenges for oil demand, supply and prices. Energy Research \& Social Science, 68, 101669.

Jeribi, A., \& Fakhfekh, M. (2021). Portfolio management and dependence structure between cryptocurrencies and traditional assets: Evidence from FIEGARCH-EVT-Copula. Journal of Asset Management. https://doi.org/10.1057/s41260-021-00211-7

Jeribi, A., \& Ghorbel, A. (2021). Forecasting developed and BRICS stock markets with cryptocurrencies and gold: Generalized orthogonal generalized autoregressive conditional heteroskedasticity and generalized autoregressive score analysis. International Journal of Emerging Markets. https://doi.org/10.1108/IJOEM-06-2020-0688

Mazur, M., Dang, M., \& Vegaa, M. (2020). COVID-19 and the March 2020 stock market crash. Evidence from S\&P1500. Finance Research Letters. https://doi.org/10.1016/j.frl.2020.101690

Narayan, P. K., \& Gupta, R. (2015). Has oil price predicted stock returns for over a century? Energy Economics, 48, 18-23.

Rizwan, M., Ahmad, G., \& Ashraf, D. (2020). Systemic risk: the impact of COVID-19. Finance Research Letters. https://doi.org/10.1016/j.frl.2020.101682 
Robiyanto, R., Hadiyatno, D., Sudjinan, S., \& Ernayani, R. (2019). Gold and capital market in Indonesia: a preview on strategy of hedging and diversification. Journal of International Studies, 12(2), 117-128.

Salisu, A. A., Swaray, R., \& Oloko, T. F. (2019). Improving the predictability of the oil-US stock nexus: The role of macroeconomic variables. Economic Modelling, 76, 153-171.

Salisu, A. A., Ebuh, G. U., \& Usman, N. (2020). Revisiting oil-stock nexus during COVID-19 pandemic: Some preliminary results. The International Review of Economics \& Finance, 69, $280-294$.

Sayed, A., \& Auret, C. (2020). Volatility transmission in the South African white maize futures market. Eurasian Economic Review, 10, 71-88.

Schneider, A., Domonoske, C. (2020). Oil prices, stocks plunge after Saudi Arabia stuns world with massive discounts. NPR. https://www.npr.org/2020/03/08/813439501/saudi-arabia-stuns-world-withmassive-discount-in-oil-sold-to-asia-europe-and-u-

Selmi, R., Mensi, W., Hammoudeh, S., \& Bouoiyour, J. (2018). Is Bitcoin a hedge, a safe haven or a diversifier for oil price movements? A comparison with gold. Energy Economics, 74, 787-801.

Sharif, A., Aloui, C., \& Yarovaya, L. (2020). Covid-19 pandemic, oil prices, stock market, geopolitical risk and policy uncertainty nexus in the US economy: Fresh evidence from the Wavelet-based approach. International Review of Financial Analysis, 70(101496), 92025040.

Vardar, G., Coşkun, Y., \& Yelkenci, T. (2018). Shock transmission and volatility spillover in stock and commodity markets: Evidence from advanced and emerging markets. Eurasian Economic Review, $8,231-288$

Zhang, D., Hu, M., \& Ji, Q. (2020). Financial markets under the global pandemic of COVID-19. Finance Research Letters, 36, 101528.

Publisher's Note Springer Nature remains neutral with regard to jurisdictional claims in published maps and institutional affiliations. 